\title{
Anisotropic Particles from LC Polymers for Optical Manipulation
}

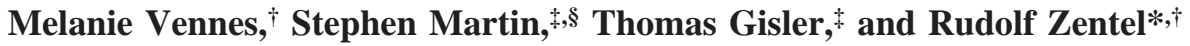 \\ Institute of Organic Chemistry, University of Mainz, Duesbergweg 10-14, D-55099 Mainz, and \\ Department of Physics-Fach M621, University of Konstanz, D-78457 Konstanz, Germany
}

Received June 14, 2006; Revised Manuscript Received September 14, 2006

\begin{abstract}
We have developed a method to convert 10 different LC acrylate monomers into colloids by dispersion polymerization. This yields nine different types of anisotropic colloids with nematic and different smectic phases. The diameter of these colloids mostly varied between 0.5 and $3.5 \mu \mathrm{m}$; it can be adjusted by variation of the solvent mixture and it can be systematically increased by seed polymerization. The polydispersity of the anisotropic colloids is thereby often below 10\%. Polarizing microscopy shows that colloids of a size between about 2 to $4 \mu \mathrm{m}$ appear to have a bipolar director configuration. Smaller colloids appear uniaxially oriented, the resolution does, however, not allow a more refined investigation of the director pattern. These anisotropic spheres (diameter between 0.7 and $3.7 \mu \mathrm{m}$ ) can be trapped with an optical tweezers. Circularly polarized light transfers a torque to the particles, enabling one to rotate them clockwise and anticlockwise, which makes these spheres attractive as actuators. The size dependence of their rotational frequency makes it additionally possible to determine changes of the director configuration with size. For a nematic colloid (P 6), it could be shown that the anisotropy stays constant from 1.6 to $3.4 \mu \mathrm{m}$.
\end{abstract}

\section{Introduction}

In recent years colloids, and especially optically anisotropic colloidal particles, have been of growing interest because they can be manipulated with optical tweezers. They have, for example, been used to demonstrate the orbital and spin angular momentum of light ${ }^{1}$ and to quantitatively measure on a micrometer-size scale viscosity in liquid media. ${ }^{2}$ Birefringent particles are of interest as potential optical switches ${ }^{3}$ and scattering polarizers ${ }^{4}$ and may be useful for microfluidic applications as stirrers and valves. ${ }^{5}$

There are different types of birefringent colloidal particles available such as fluoropolymer latex particles, inorganic particles (e.g., calcium carbonate vaterite) and particles out of liquid crystals. ${ }^{6}$ One disadvantage of most fluoropolymers and inorganic particles is their anisotropic shape. Birefringent colloids from LC polymers, on the contrary, are usually spherical at particle sizes useful for optical tweezers (around $1 \mu \mathrm{m}$ ). Liquid crystal (LC) emulsions were mostly prepared by either extrusion of a liquid-crystalline material into a co-flowing liquid stream, ${ }^{7}$ leading to highly monodisperse particles with controllable sizes ranging from some tens to hundreds of micrometers, or by dropping a solution of the liquid crystal into the dispersion agent, ${ }^{6,8}$ leading to particle sizes from about $100 \mathrm{~nm}$ to some micrometers. However both methods have their flaws. The coflowing stream procedure has a very low yield of particles and becomes impractical when the viscosity of the particle material becomes too high, whereas the dispersion agent method has very high polydispersity for particles over a few hundred nanometers. For the stabilization of the LC colloids, mixtures of photopolymerizable diacrylates and photoinitiator were used and polymerized after the droplet formation by UV-irradiation. $3,6,8,9$ However, in each case only one commercially available monomer (RM257 or RMM14) was investigated. To our

\footnotetext{
* Corresponding author. Fax: (+49) 6131/39-24778. E-mail zentel@uni-mainz.de.

$\dagger$ Institute of Organic Chemistry, University of Mainz.

$\doteqdot$ Department of Physics-Fach M621, University of Konstanz.

$\S$ Current address: Australian National University, Research School of Chemistry, Canberra, ACT 0200, Australia.
}

knowledge there are no systematic studies about the preparation of anisotropic colloids from different LC materials with this method, and of the influence of the LC material and its phases on the properties of the resulting colloids.

Another possible method to produce colloids of LC polymers is to transfer the prepared polymer into spherical objects via the miniemulsion process, as reported recently. ${ }^{10,11}$ Different side-chain ${ }^{10}$ and main-chain ${ }^{11}$ LC polymers were used, but in this case the sizes of the colloids were only in the range of about $50-300 \mathrm{~nm}$, which is too small for a direct observation with a polarizing microscope and too small for manipulation with optical tweezers.

In this work, we report about the preparation of various anisotropic colloids of different smectic and nematic acrylate polymers by a special modification of a precipitation polymerization called dispersion polymerization, ${ }^{12}$ which we recently described for the first time for this purpose. ${ }^{13}$ These colloids have diameters of a few micrometers and can therefore be used for experiments with optical tweezers, of which we show some examples.

\section{Results and Discussion}

The starting point of this work was the attempt (1) to broaden the materials basis of LC colloids prepared via dispersion polymerization, (2) to correlate properties of the starting monomers (solubility, phase) with the LC colloids obtained, and (3) to control size and size distribution. Of particular importance was the attempt to prepare colloids of larger size, as larger colloids are more suitable for experiments with optical tweezers. Therefore, we synthesized a large number of different acrylate and methacrylate monomers with different spacer lengths, mesogenic units, and polarities (see Scheme 1). The monomers with ethylene oxide spacer (M 1 and M 2) are, for example, more hydrophilic than the other acrylate monomers. To compare similar polymers with different spacer lengths $\left(2,6\right.$, or $11 \mathrm{CH}_{2}-$ groups) and different mesogenic units (two- or three-ring mesogens), the monomers $\mathbf{M} \mathbf{3}$ to $\mathbf{M} \mathbf{1 3}$ were synthesized. The chiral monomers M 11 to $\mathbf{M} 13$ were synthesized in analogy to ferroelectric polysiloxanes and may lead to colloids with an 
Scheme 1. Synthesized Monomers Used in This Work
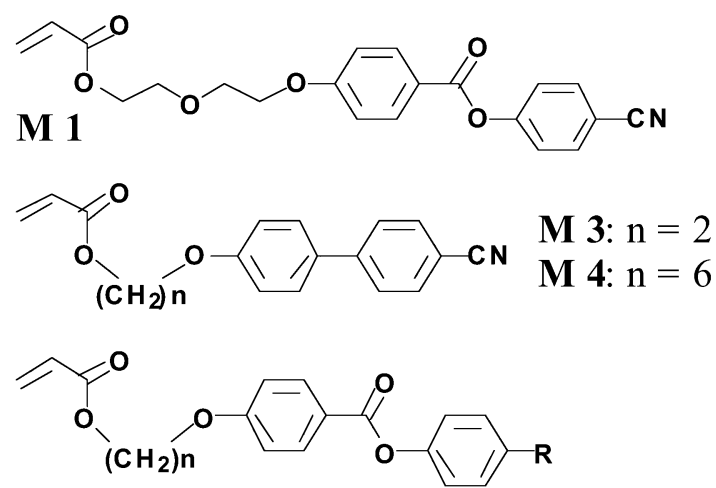

M 5: $\mathrm{n}=2 ; \mathrm{R}=\mathrm{CN}$

M 6: $\mathrm{n}=6 ; \mathrm{R}=\mathrm{CN}$

M 7: $\mathrm{n}=6 ; \mathrm{R}=\mathrm{C}_{6} \mathrm{H}_{4} \mathrm{CN}$

M 8: $\mathrm{n}=2 ; \mathrm{R}=\mathrm{OCH}_{3}$

M 9: $\mathrm{n}=6 ; \mathrm{R}=\mathrm{OCH}_{3}$

M 10: $\mathrm{n}=6 ; \mathrm{R}=\mathrm{C}_{6} \mathrm{H}_{4} \mathrm{OCH}_{3}$

Table 1. Phase Behavior of the Monomers and Polymers

\begin{tabular}{|c|c|c|c|}
\hline monomer & phase behavior, ${ }^{\circ} \mathrm{C}$ & polymer & phase behavior, ${ }^{\circ} \mathrm{C}$ \\
\hline M 1 & c $87 \mathrm{i}$ & P 1 & g $32 \mathrm{i}$ \\
\hline M 2 & c $59 \mathrm{i}$ & P $2^{17,18}$ & $\mathrm{~s}_{\mathrm{E}, \mathrm{glass}} 55 \mathrm{~s}_{\mathrm{E}} 113 \mathrm{i}$ \\
\hline M 3 & c $85 \mathrm{i}$ & $\mathbf{P} \mathbf{3}^{19}$ & g $50 \mathrm{n} 112 \mathrm{i}$ \\
\hline M 4 & c $69 \mathrm{i}$ & $\mathbf{P} \mathbf{4}^{19,20}$ & $\mathrm{~g} 38 \mathrm{~s}_{\mathrm{A}} 115 \mathrm{n} 123 \mathrm{i}$ \\
\hline M 5 & c $111 \mathrm{i}$ & P $\mathbf{5}^{21,22}$ & g 75 n $110 \mathrm{i}$ \\
\hline M 6 & c $72 \mathrm{i}$ & P $\mathbf{6}^{21,22}$ & g 33 n 133 i \\
\hline M 7 & c $106 \mathrm{n}\left(<180^{\#}\right)$ & P $7^{23}$ & g $90 \mathrm{~s} 220 \mathrm{i}$ \\
\hline M 8 & c $92 \mathrm{i}$ & P $\mathbf{8}^{21,22}$ & g 62 n $116 i$ \\
\hline M 9 & c $53 \mathrm{i}$ & P $\mathbf{9}^{21,22}$ & g $22 \mathrm{~s}_{\mathrm{A}} 90 \mathrm{n} 109 \mathrm{i}$ \\
\hline M 10 & c 96 n 258 i & P 10 $\mathbf{1 0}^{21}$ & g $56 \mathrm{k}_{1} 110 \mathrm{k}_{2} 118 \mathrm{~s} 138 \mathrm{n} 257$ \\
\hline M 11 & c $56 \mathrm{i}$ & $\mathbf{P} 11^{13}$ & $\mathrm{~s}_{\mathrm{X}} 76 \mathrm{~s}_{\mathrm{A} / \mathrm{C}} * 122 \mathrm{i}$ \\
\hline M 12 & c $74 \mathrm{i}$ & P 12 & c 92 lc $107 \mathrm{i}$ \\
\hline M 13 & $c_{1} 30 c_{2} 59 \mathrm{~s} 65 \mathrm{i}$ & $\mathbf{P} \mathbf{1 3}^{24}$ & $\mathrm{~s}_{\mathrm{X}} 56 \mathrm{~s}_{\mathrm{C}}^{*} 158 \mathrm{i}$ \\
\hline
\end{tabular}

${ }^{a}$ Key: $\mathrm{c}=$ crystalline, $\mathrm{i}=$ isotropic, $\mathrm{g}=$ glassy, $\mathrm{n}=$ nematic, $\mathrm{s}=$ smectic, $\mathrm{s}_{\mathrm{E}}=$ smectic $\mathrm{E}, \mathrm{s}_{\mathrm{A}}=$ smectic $\mathrm{A}, \mathrm{sx}_{\mathrm{X}}=$ higher-ordered smectic, $\mathrm{s}_{\mathrm{C}} *$ $=$ chiral smectic $\mathrm{C}, \mathrm{lc}=$ liquid crystalline, and \# thermal polymerization occurred).

especially low symmetry. Such liquid-crystalline colloids from ferroelectric LC materials with a chiral smectic $C^{*}$ phase are interesting because they must have a polar axis, if the particle gets small enough (below the pitch of the superstructure). ${ }^{16}$

Most of the monomers and their corresponding LC polymers have already been described in the literature. Therefore, the phase behavior of the polymers is also already known (see Table 1). As we only had small amounts of the polymers available, we only checked by DSC measurements and polarizing microscopy for indications of the same phases. For that, we used the bulk polymer that we obtained from larger agglomerates remaining as residue after the centrifugation of the dispersion polymerization batches. Generally our phase assignment was consistent with the literature. The phase transition temperatures were usually slightly reduced, which may be due to the lower molecular weights and the presence of the steric stabilizer (graftet cellulose chains) necessary for the dispersion polymerization.

Polymer $\mathbf{P} 1$ (not described so far) turned out to be not liquidcrystalline. In contrast, polymer $\mathbf{P} \mathbf{2}$ is one of the few literatureknown liquid-crystalline polymers with ethylene oxide spacer that has moderate phase transition temperatures. ${ }^{17,18}$ According to literature, it possesses a higher ordered smectic E phase. This smectic phase could not be verified with our methods. Polymer
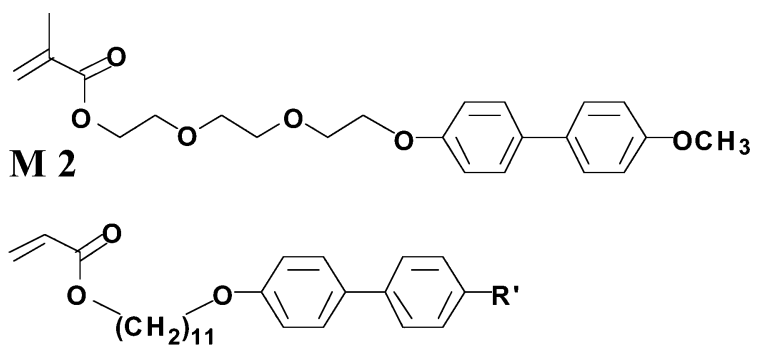

$M 11: R^{\prime}=0 \prod_{0}^{c \mid}$

$\mathrm{M} \mathrm{12:} \mathrm{R}^{\prime}=\underbrace{\mathrm{C}_{1}^{\mathrm{Cl}}}_{\mathrm{O}}$

$M$ 13: $\mathrm{R}^{\prime}=\underbrace{\mathrm{O}}_{\mathrm{O}} \mathrm{NO}_{2}$

$\mathbf{P} \mathbf{4}$ is claimed to have-in addition to a smectic and a nematic phase - a reentrant nematic phase, but without giving any indication on how this was proven. ${ }^{19,20}$ We could not find any evidence for the reentrant phase and assume that the polymer is just smectic and nematic. The polymers $\mathbf{P ~ 3 , P ~ 5 , ~ P ~ 6 , ~ a n d ~}$ $\mathbf{P} \mathbf{8}$ have nematic phases, whereas the polymers $\mathbf{P} \mathbf{9}$ and $\mathbf{P} \mathbf{1 0}$ show additionally smectic phases. These phases could be identified by texture observation in agreement with literature data. For the chiral polymers $\mathbf{P} \mathbf{1 1}$ to $\mathbf{P} \mathbf{1 3}$ smectic LC phases were found, but due to the high viscosity of the samples they could not be aligned well enough to differentiate between different phases by texture observation.

We prepared colloids from the synthesized monomers by dispersion polymerization, which is a special case of a "precipitation polymerization". ${ }^{12-15}$ At the beginning of this process, the monomer, a steric stabilizer like hydroxypropyl cellulose (HPC) and a radical initiator like dibenzoyl peroxide (DBPO) are dissolved in a solvent, in which the LC polymer itself is insoluble. The radicals formed during thermal decomposition of the initiator do not only start the polymerization of the monomer, but also abstract hydrogen from the hydroxylpropyl cellulose chain, leading to a graft polymerization of LC polymer onto HPC. This happens until the polymer including the graftpolymer precipitates and forms a sterically stabilized micelle. After the formation of the polymer micelles, further polymerization proceeded mostly in the micelles, which grow with time, leading to sterically stabilized polymer spheres.

The choice of a suitable solvent/nonsolvent system is very important for this process. ${ }^{12}$ For most of the monomers we used, mixtures of ethanol (EtOH) and 2-methoxyethanol (ME) proved to be suitable. Previous experiments have shown that the size of the colloids can be tuned best by choice of the solvent, whereas the amount of initiator and stabilizer only had minor effects on the particle size. Thus, for these studies we varied mostly the mixing ratio of the solvents in order to get colloids of different size and polydispersity. Since the polydispersity of the obtained colloids may depend on to the polydispersity of the HPC used, we fractionated HPC (see Experimental Part) for these experiments. The results of the experiments are summarized in Table 2 and Figure 1. The size of the colloids was determined with an optical microscope. Optical microscope images of the colloids are presented in Figure 2. 
Table 2. Colloid Diameters and Standard Deviations for Dispersion Polymerization with Different Solvent Mixtures and Monomers

\begin{tabular}{|c|c|c|c|c|c|c|c|c|c|c|}
\hline \multirow[b]{2}{*}{ solvent } & \multicolumn{10}{|c|}{$\mathrm{d}(\Delta \mathrm{d}) / \mu \mathrm{m}$} \\
\hline & M 1 & M 2 & M 3 & M 4 & M 5 & M 6 & M 7 & M 8 & M9 & M 11 \\
\hline EtOH & $\begin{array}{c}0.83 \\
(0.28)\end{array}$ & $\begin{array}{c}0.75 \\
(0.12)\end{array}$ & $\begin{array}{c}0.66 \\
(0.06)\end{array}$ & $\begin{array}{c}0.74 \\
(0.08)\end{array}$ & $a$ & $\begin{array}{c}0.69 \\
(0.05)\end{array}$ & $a$ & $a$ & $\begin{array}{c}0.78 \\
(0.08)\end{array}$ & $\begin{array}{c}0.99 \\
(0.09)\end{array}$ \\
\hline EtOH/ME 10:1 & $a$ & $\begin{array}{c}0.85 \\
(0.26)\end{array}$ & $\begin{array}{c}0.76 \\
(0.07)\end{array}$ & $\begin{array}{c}0.89 \\
(0.18)\end{array}$ & $\begin{array}{c}0.71 \\
(0.08)\end{array}$ & $\begin{array}{c}0.75 \\
(0.05)\end{array}$ & $a$ & $\begin{array}{c}0.90 \\
(0.09)\end{array}$ & $\begin{array}{c}1.10 \\
(0.18)\end{array}$ & $\begin{array}{c}0.84 \\
(0.13)\end{array}$ \\
\hline EtOH/ME 5:1 & $a$ & $a$ & $a$ & $\begin{array}{c}1.11 \\
(0.36)\end{array}$ & $a$ & $a$ & $a$ & $a$ & $a$ & $\begin{array}{c}1.13 \\
(0.17)\end{array}$ \\
\hline EtOH/ME 4:1 & $a$ & $a$ & $a$ & $a$ & $a$ & $\begin{array}{c}0.83 \\
(0.06)\end{array}$ & $a$ & $a$ & $a$ & $\begin{array}{c}1.00^{d} \\
(0.50)\end{array}$ \\
\hline EtOH/ME 2:1 & $a$ & $a$ & $\begin{array}{c}0.87 \\
(0.15)\end{array}$ & $\begin{array}{c}1.16 \\
(0.33)\end{array}$ & $\begin{array}{c}0.76 \\
(0.10)\end{array}$ & $\begin{array}{c}1.01 \\
(0.08)\end{array}$ & $\begin{array}{c}0.70 \\
(0.08)\end{array}$ & $\begin{array}{c}1.21 \\
(0.15)\end{array}$ & $a$ & $a$ \\
\hline EtOH/ME 1:1 & $a$ & $\begin{array}{c}1.37 \\
(0.30)\end{array}$ & $\begin{array}{c}1.82 \\
(0.62)\end{array}$ & $\begin{array}{c}1.52 \\
(0.61)\end{array}$ & $\begin{array}{c}1.03 \\
(0.29)\end{array}$ & $\begin{array}{c}1.16 \\
(0.07)\end{array}$ & $\begin{array}{c}0.78 \\
(0.08)\end{array}$ & $\begin{array}{l}3.3 \\
(2.7)\end{array}$ & $\begin{array}{c}3.3 \\
(2.7)\end{array}$ & $a$ \\
\hline EtOH/ME 2:3 & $a$ & $a$ & $a$ & $a$ & $a$ & $\begin{array}{c}1.74 \\
(0.75)\end{array}$ & $\begin{array}{c}0.83 \\
(0.08)\end{array}$ & $a$ & $a$ & $a$ \\
\hline EtOH/ME 1:2 & $a$ & $a$ & $\begin{array}{c}4.5 \\
(3.7)\end{array}$ & $\begin{array}{c}1.98 \\
(0.56)\end{array}$ & $\begin{array}{c}1.44 \\
(0.58)\end{array}$ & $\begin{array}{c}3.65 \\
(2.95)\end{array}$ & $\begin{array}{c}0.95 \\
(0.10)\end{array}$ & $\begin{array}{c}12 \\
\text { (11) }\end{array}$ & $b$ & $a$ \\
\hline EtOH/ME 1:5 & $a$ & $a$ & $a$ & $\begin{array}{c}2.1 \\
(1.1)\end{array}$ & $a$ & $\begin{array}{c}2.4 \\
(1.1)\end{array}$ & $\begin{array}{c}0.63 \\
(0.10)\end{array}$ & $a$ & $a$ & $a$ \\
\hline EtOH/ME 1:10 & $a$ & $a$ & $\begin{array}{c}11.5 \\
(10.5)^{c}\end{array}$ & $a$ & $\begin{array}{c}4.4 \\
(3.6)^{c}\end{array}$ & $a$ & $a$ & $b$ & $a$ & $a$ \\
\hline ME & $a$ & $a$ & $a$ & $\begin{array}{c}3.6^{e} \\
(3.1)\end{array}$ & $b$ & $f$ & $\begin{array}{c}0.81 \\
(0.11)\end{array}$ & $a$ & $a$ & $a$ \\
\hline
\end{tabular}

${ }^{a}$ Has not been performed. ${ }^{b}$ No colloids. ${ }^{c}$ Slightly turbid. ${ }^{d}$ Additionally agglomerates. ${ }^{e}$ Additionally larger nonspherical objects. ${ }^{f}$ Only a few colloids up to $30 \mu \mathrm{m}$.

As a result it was possible to polymerize the monomers $\mathbf{M} \mathbf{1}$ to $\mathbf{M} 9$ and $\mathbf{M} 11$ with EtOH/ME mixtures into sterically stabilized LC colloids of different size (mostly between 0.5 and $3.5 \mu \mathrm{m})$. The graphs in Figure 1 show for all systems a strong increase in diameter and polydispersity with increasing amount of ME. This is in agreement with literature. ${ }^{12} \mathrm{ME}$ is thereby the better solvent as evidenced by the fact that some polymers (P3, P 5, P 8, and P 9) are soluble in it and do not precipitate at all. The increase of diameter is about exponential. Concerning differences between the monomers Figure 1 and Table 2 show that the monomers containing cyano groups still show colloid formation at large ME concentrations. The monomers featuring a C6 spacer can even be polymerized to colloids in pure ME. For the monomers containing a methoxy group, however, at least a third of the solvent mixture must be ethanol to yield colloids.

These results can be rationalized in the following way: ${ }^{12,14,15}$

Solvent mixtures with a large amount of ethanol are poor solvents for the newly formed oligomers and polymers. As a result of the early precipitation of the polymers more particle nuclei occur and thus more and smaller particles are formed finally. At the same time secondary nucleation happens rarely. Thus, a narrow size distribution is obtained for solvent mixtures rich in ethanol.

In contrast, for better solvent mixtures (more ME) the polymers precipitate later. This leads to less particle nuclei which grow to bigger lattices. Additionally, the polydispersity increases. This is likely due to secondary nucleations resulting from an oversaturated solution and the smaller amounts of colloids present.

Concerning the different monomers the success of colloid formation depends on the molecular structure of the monomers as follows: Large apolar hydrocarbon segments seem to be hardly compatible with this type of dispersion polymerization. From the monomers with C11 spacers (M 11-M 13) only one can be converted into colloids; from the three monomers with three benzene rings in the mesogenic structure (M 7, M 10, and $\mathbf{M}$ 13), again only one (M 7) yields colloids. This one has a highly polar cyano group directly linked at the mesogen. In this context it must be noted that for the monomers $\mathbf{M} \mathbf{1 0}$, M 12, and M 13 that did not lead to colloids (or only to few colloids and agglomerates) for EtOH/ME mixtures, other
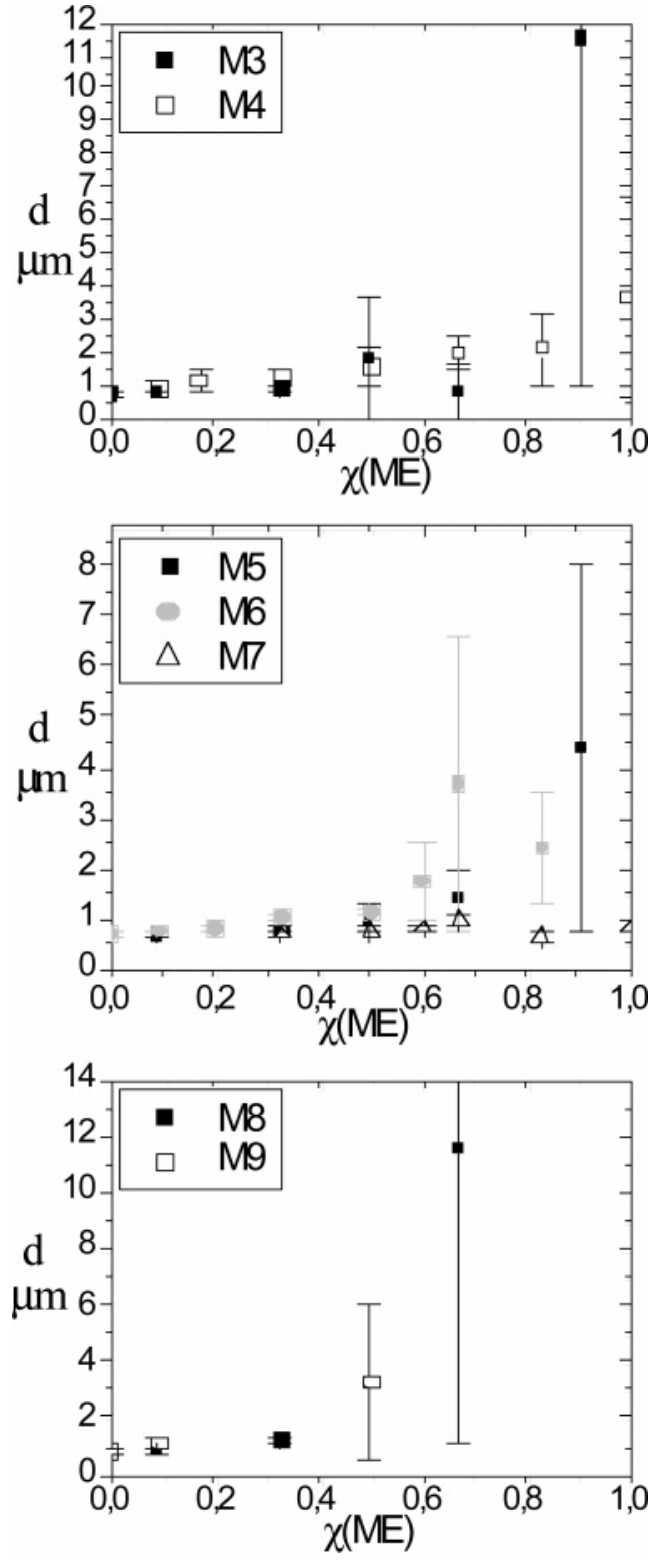

Figure 1. Particle diameter vs mole fraction (ME) for M 3 to M 9. 


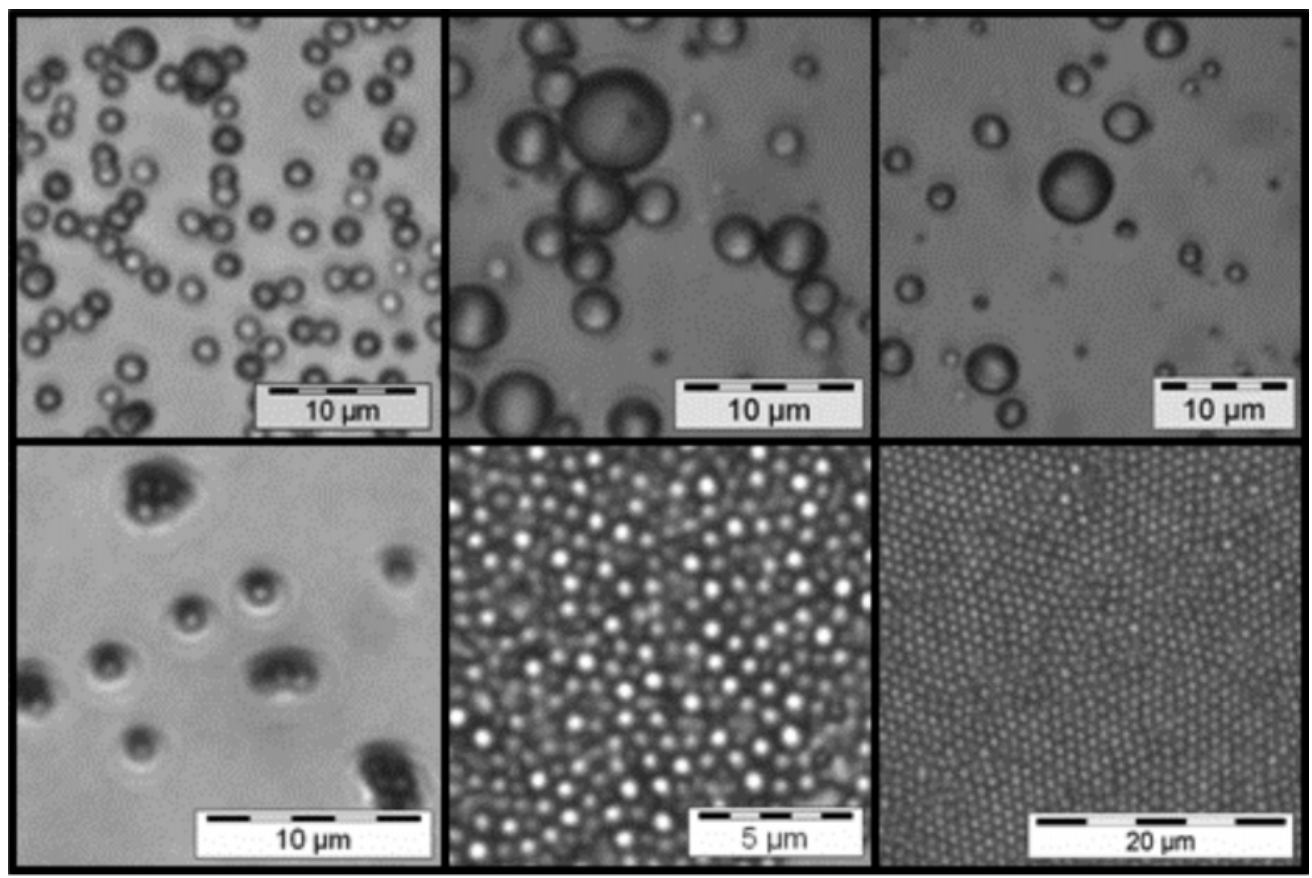

Figure 2. Optical microscope images of colloids of different polymers (top, broader size distribution; top left, $\mathbf{P} 4$ (EtOH/ME 1:5); top middle, $\mathbf{P} 6$ (EtOH/ME 1:2); top right, $\mathbf{P} 9$ (EtOH/ME 1:1); bottom, narrow size distribution; bottom left, $\mathbf{P} 7$ (EtOH/ME 1:1); bottom middle, $\mathbf{P} 3$ (EtOH/ ME 2:1); bottom right, $\mathbf{P} 6$ (EtOHME 2:1). The pictures were taken either on sedimented mono- and multilayers (bottom right and middle) or on floating colloids (bottom left and top).

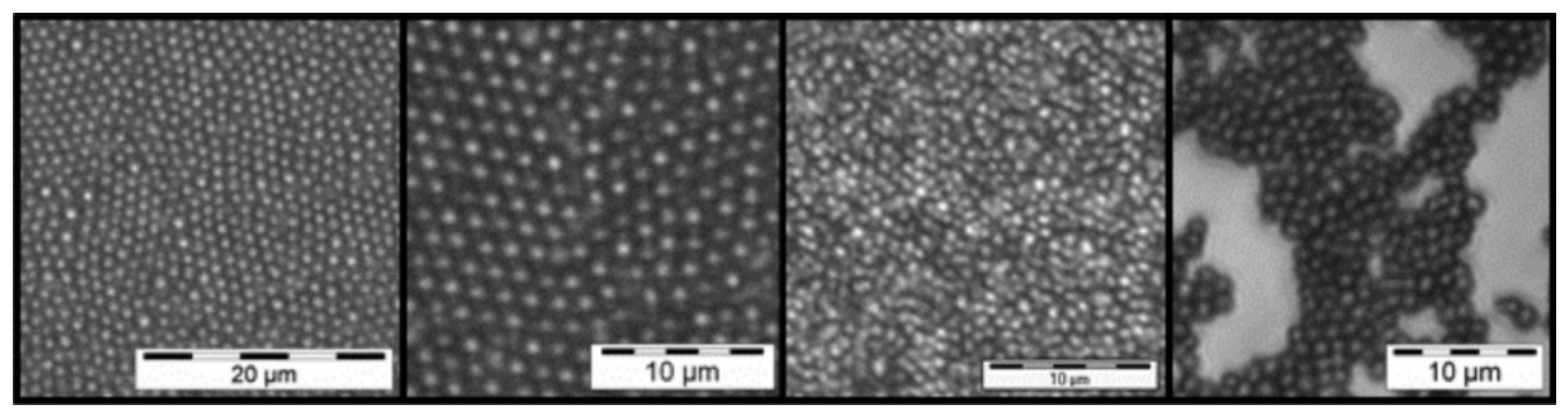

Figure 3. Optical microscope images of colloids prepared by "normal" dispersion polymerization and seed polymerization (left, $\mathbf{P} 6$ (EtOH/ME $1: 1$; diameter $=1.16 \pm 0.07)$; middle left, $\mathbf{P} 6$ (seed polymerization in EtOH/ME 1:1; diameter $=1.57 \pm 0.12 \mu \mathrm{m}) ;$ middle right, $\mathbf{P} 11($ EtOH; diameter $=0.99 \pm 0.09 \mu \mathrm{m})$; right, $\mathbf{P} 11$ (seed polymerization in EtOH; diameter $=1.25 \pm 0.12 \mu \mathrm{m})$.

solvents like mixtures of $\mathrm{ME}$ or EtOH and THF were also tried. However, again no or only a few single colloids and other solid pieces, agglomerates etc. were obtained. Concerning the size of the colloids, the comparison of similar monomers with $\mathrm{C} 2$ spacers and C6 spacers shows that for a given solvent mixture (at least for solvent mixtures where the colloids still have a narrow distribution) the colloids with $\mathrm{C} 6$ spacers are a bit bigger. However, in most cases no colloids were obtained (M 10 and M 13).

As a result of these experiments it is possible to make colloids with diameters mostly between about 0.5 to $3.5 \mu \mathrm{m}$, whereas bigger colloids were only obtained in limited numbers together with smaller colloids in samples with a very broad size distribution. In addition the large colloids are only accessible for some monomers. To get bigger colloids with a narrow distribution, a seed polymerization with the monomers M 6 and M 11 was developed. For this purpose solvent mixtures that still lead to colloids with a narrow size distribution (EtOH/ME 1:1 for M 6, pure EtOH for M 11) were used. The seed polymerization was started like the other dispersion polymerizations, but additionally every $30 \mathrm{~min}$ a solution of monomer in the used solvent mixture was added (in total nine times, see Experimental Part). As a result it can be shown that seed polymerization is a general method to increase the diameter of the LC colloids, but a lot of monomer is needed. In theory doubling the amount of monomer should increase the radius by approximately $25 \%$ (assuming a doubling of mass). The experiments showed a radius increase less than expected. For monomer M 6 a quadruplication of the amount of monomer increases the diameter from $1.16 \pm 0.07$ to $1.57 \pm 0.12 \mu \mathrm{m}$ (theroretically $1.84 \mu \mathrm{m}$ ), whereas for monomer $\mathbf{M} \mathbf{1 1}$ the quadruplication leads to a diameter of $1.25 \pm 0.12 \mu \mathrm{m}$ (theoretically $1.57 \mu \mathrm{m}$ ) instead of $0.99 \pm 0.09 \mu \mathrm{m}$. In both cases the big colloids - not accessible by direct polymerization - still have a narrow size distribution of about or less than $10 \%$ (see Figure 3).

In a next step, the colloid suspensions were investigated by polarizing microscopy. All colloids except the ones from monomer M 1 show evidence of birefringence when viewed between crossed polarizers, whereupon the colloids of the monomers with C2 spacers (M 3, M 5, M 8) seem a bit less bright/birefringent than the others. This may be a result of their higher $T_{\mathrm{g}}$-values, which make it more difficult to establish the LC phase and to reach the stable director configuration. For small diameters up to about $1.8 \mu \mathrm{m}$ the colloids show a uniform birefringence; they appear as spots whose brightness fluctuate 


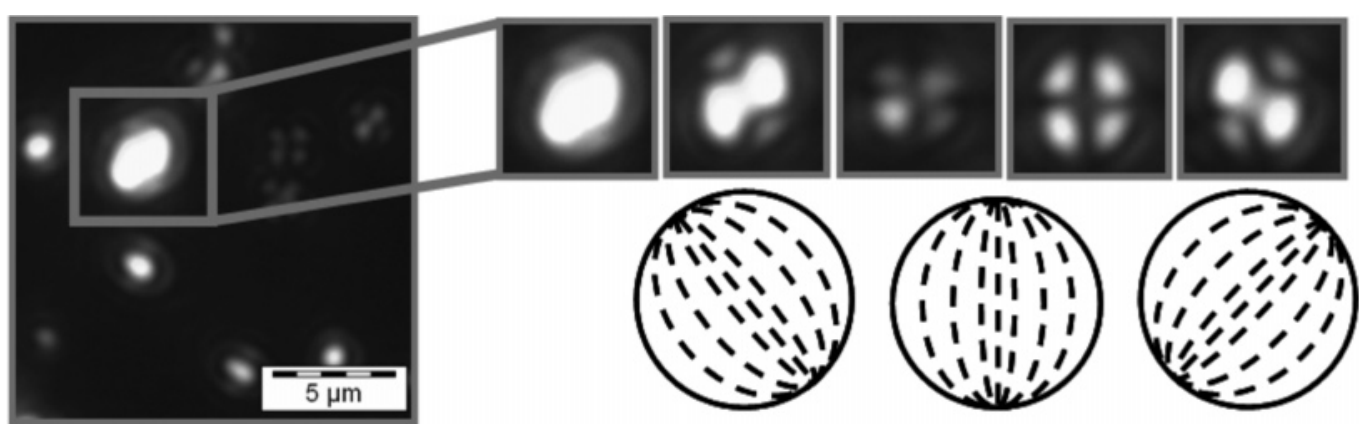

Figure 4. Polarizing microscope images of colloids of $\mathbf{P} 6$ (EtOH/ME 2:3) (sample holder was rotated).

when they rotate due to Brownian motion (see movie 1 in the Supporting Information). The optical resolution of the microscope is, however, too low to characterize their director pattern in more detail. As soon as the particles get big enough (diameter approximately $2-4 \mu \mathrm{m}$ ), maltese cross and "baseball" type patterns can be found. Figure 4 shows polarizing microscope images of a dried sample of colloids of $\mathbf{P}$ 6. The sample holder was rotated; thereby the texture changes from a maltese cross to a "baseball" type pattern. This indicates that the colloids of intermediate size have a bipolar director configuration (see Figure 3). Larger colloids ( $>4 \mu \mathrm{m}$ ) show usually a more complex director pattern.

The prepared colloids are generally suitable for use in optical tweezers. For our experiments we used a standard optical tweezers setup with a circularly polarized trapping beam. While it was very difficult to trap the small colloids (below $1.6 \mu \mathrm{m}$ ) for any significant amount of time, colloids of an intermediate size $(1.8-2.5 \mu \mathrm{m})$ could be trapped with ease and held for longer times. However, much larger colloids present a problem in that they sediment rather quickly, resulting in undesired effects such as sticking to the sample surface. When trapped, the spheres could be typically held in the tweezer for several minutes before escaping due to thermal fluctuations. This allows various manipulations and investigations. When the birefringent colloids are trapped under circularly polarized light, a torque $T$ is transferred to the anisotropic particle and it rotates. This rotation force is countered by the Stokes drag, resulting in a constant rotation frequency $f$ given by

$$
f=T /\left(8 \pi n r^{3}\right)
$$

where $r=$ radius and $n=$ solvent viscosity, in this case for water.

Viewed between crossed polarizers the particles director field depolarizes the light, and, provided there is a bipolar director field in the particle, appears as a spot whose brightness is dependent on the angle at which it is aligned between the crossed polarizers, resulting in an intensity fluctuation, $I=\sin ^{2}(2 \theta)$. For particles that are big enough (diameter above $2 \mu \mathrm{m}$ ) a change of the optical texture during rotation can also be observed. However slightly defocusing the camera lens can blur out the detail somewhat, and we again see an intensity relationship $I=\sin ^{2}(2 \theta)$.

For our experiments we trapped and rotated anisotropic colloids of $\mathbf{P ~ 4 , P ~ 6 , P ~ 9 , ~ a n d ~} \mathbf{P} 11$ with different sizes between 0.7 and $3.7 \mu \mathrm{m}$ at a constant laser power (see movie 2 in the Supporting Information). By changing the position of the quarter-waveplate (rotation of $90^{\circ}$ or turning around $180^{\circ}$ ) and thus the rotational sense of the polarized light, the direction of the rotation of the colloids could be changed between clockwise and anticlockwise. One of the films shows a trapped colloid that picks-up another colloid to orbit around it (see movie 3 in the Supporting Information). This shows the potential of the anisotropic colloids as actuators.

Rotation of the colloids in the laser field allows it to study the quality of the LC ordering (director configuration) and its dependence on the size of the colloids. Generally, the rotation speed of the colloids decreases as the size increases as predicted by eq I for a constant torque $T$. The efficiency of the torque transfer is dependent on the anisotropy of the colloids and thus the director configuration. To investigate if the anisotropy/ birefringence of the colloids changes with size and to determine the size limit at which the colloids get polycrystalline, we measured the rotational frequency for colloids of different diameter and plotted $\log (f)$ vs $\log (r)$ (see Figure 5). If the

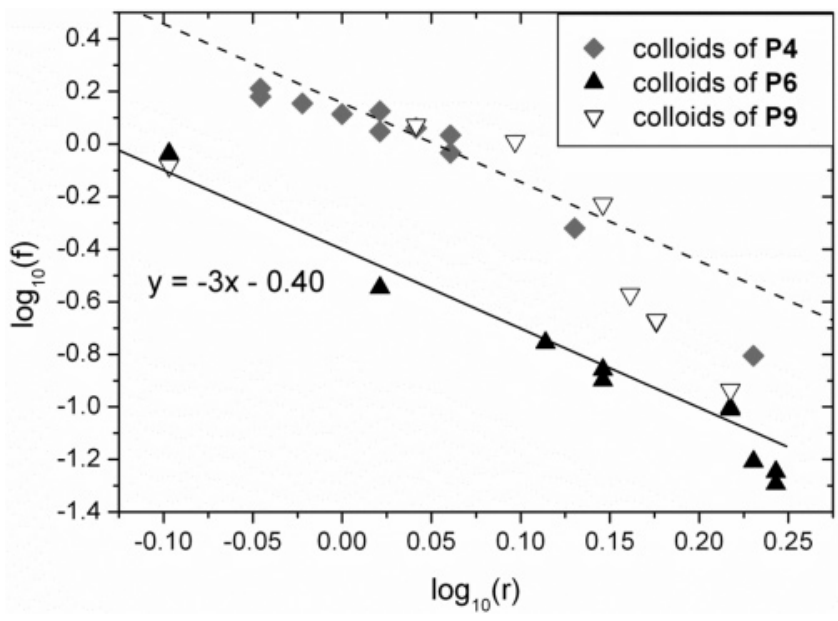

Figure 5. Dependence of $\log (f)$ on $\log (r)$ for colloids of $\mathbf{P} \mathbf{4}, \mathbf{P ~ 6}$, and $\mathbf{P}$ 9. Also displayed as a guide are lines of exponent $\gamma=-3$ relating to the constant torque assumption of eq I.

anisotropy does not change, this plot should give a straight line with a slope of -3 and a $y$ intercept of $\log (T /(8 \pi n)$. In contrast, if there is any change in the torque with particle size, there is a deviation from a straight line on the graph. Thus, it is possible to detect changes in the director pattern below the limit of the optical resolution.

For various colloids of $\mathbf{P} \mathbf{6}$ ranging in size from 1.6 to 3.5 $\mu \mathrm{m}$ we found a slope of -3 over nearly the full size range studied (see Figure 5). Thus, torque and anisotropy/birefringence remain constant suggesting the particles do not change their director pattern in the size range measured. Only colloids of diameters above $3.4 \mu \mathrm{m}$ start to deviate a little bit from the graph, indicating that the birefringence starts to decrease. Small colloids of $\mathbf{P} \mathbf{6}$ with $0.7 \mu \mathrm{m}$ diameter are beginning to approach the size of the trapping laser focus $(\sim 0.5 \mu \mathrm{m})$ at which point assumptions made in the formulation of eq I begin to become invalid. As a result, rotation frequencies of these smaller particles are not included for this particular analysis. 
For colloids of $\mathbf{P} \mathbf{4}$ or $\mathbf{P} \mathbf{9}$, however, the measured points do not all fit on a straight line (see Figure 5). For colloids of $\mathbf{P} \mathbf{4}$ starting from small spheres of about $1.8 \mu \mathrm{m}$ the slope of the graph begins to decrease more sharply with particle size, suggesting for eq I that the absorbed torque starts to decrease greater than predicted with increasing size. It is apparent from this that the anisotropy/birefringence decreases with increasing size of the colloids. For colloids of $\mathbf{P} \mathbf{9}$ a similar trend is observed to a much greater extent. Colloids of $\mathbf{P} \mathbf{1 1}$ generally rotate very slowly, probably because they are less birefringent than the other colloids.

Finally it is interesting to note that colloids of the polymer P 6 are nematic and follow the simple theory for size dependence, which indicates that their anisotropy remains constant. In contrast, for colloids of the polymers $\mathbf{P} \mathbf{4}$ and $\mathbf{P} \mathbf{9}$, which are smectic, the anisotropy changes with size. This may be a result of competing orientational tendencies in smectic colloids with curved or straight smectic layers, as observed for much smaller smectic colloids by TEM measurements ${ }^{10}$ (see Supporting Information). This effect would of course not arise with a nematic liquid crystal structure.

\section{Conclusion}

Dispersion polymerization allows the conversion of many LC acrylate monomers directly into spherical, but optically anisotropic colloids possessing nematic or various smectic phases at ambient temperature. These colloids in most instances have a bipolar director configuration. It is additionally possible with this method to vary the size of the colloids and to obtain a relatively low size distribution. Because of their optical anisotropy the particles can be rotated with circularly polarized light. This makes them attractive as actuators to rotate other colloids.

\section{Experimental Part}

Commercial chemicals were used without further purification. The hydroxypropyl cellulose was fractionated according to the literature ${ }^{25}$ and the fraction with $M_{\mathrm{n}}=82020$ and $M_{\mathrm{w}}=138000$ $\mathrm{g} / \mathrm{mol}$ was used for the dispersion polymerization. NMR spectra were recorded on a Bruker $300 \mathrm{MHz}$ spectrometer. FT-IR spectra were measured on a Bruker Vector 22 FTIR spectrometer. Mass spectroscopy was performed on a Finnigan MAT 90 spectrometer. Polarizing microscopy was performed with a Zeiss Jenapol SL 100microscope. DSC measurements were performed with a DSC 7 of Perkin-Elmer.

Synthesis of the Monomers. The monomers were synthesized according to literature or standard procedures for etherifications and esterifications (for references, see Table 1).

4-[2-(2-Hydroxyethoxy)ethoxy]benzoic Acid. A solution of $44.55 \mathrm{~g}(794 \mathrm{mmol})$ of potassium hydroxide, $50.09 \mathrm{~g}(363 \mathrm{mmol})$ of 4-hydroxybenzoic acid, a pinch of potassium iodide, $60 \mathrm{~mL}$ of water, and $140 \mathrm{~mL}$ of ethanol was refluxed, and $42 \mathrm{~mL}$ (398 mmol) of 2-(2-chloroethoxy)ethanol was slowly added dropwise. After that the solution was refluxed for 2 days. The solvent was removed under reduced pressure and the residue was dissolved in $250 \mathrm{~mL}$ of water. Impurities were removed by extracting the aqueous phase with diethyl ether. Then $6 \mathrm{~N}$ hydrochloric acid was added to the aqueous phase at $50{ }^{\circ} \mathrm{C}$. The precipitate formed during cooling to $0{ }^{\circ} \mathrm{C}$ was isolated by filtration and recrystallized from diethyl ether/ acetone 3:1 or ethyl acetate.

Yield: $33.23 \mathrm{~g}(40.5 \%)$ of colorless needles, $\mathrm{mp} 118^{\circ} \mathrm{C}$.

FT-IR (ATR): $\tilde{v}=3338(\mathrm{O}-\mathrm{H}), 2939,2887(\mathrm{C}-\mathrm{H}), 2663,2552$ $(\mathrm{O}-\mathrm{H}), 1677(\mathrm{C}=\mathrm{O}), 1605(\mathrm{C}=\mathrm{C}), 1579,1428,1254,1171,1130$, $1051,939,772,649$.

${ }^{1} \mathrm{H}$ NMR (DMSO- $\left.d_{6}\right): \delta=12.54(\mathrm{bs}, 1 \mathrm{H},-\mathrm{COOH}) ; 7.87(\mathrm{~d}$, $2 \mathrm{H}$, Ar-H, ortho to $-\mathrm{COOH}) ; 7.02$ (d, $2 \mathrm{H}, \mathrm{Ar}-\mathrm{H}$, meta to $-\mathrm{COOH})$; $4.63(\mathrm{bs}, 1 \mathrm{H},-\mathrm{OH}) ; 4.16\left(\mathrm{t}, 2 \mathrm{H},-\mathrm{CH}_{2} \mathrm{O}-\right) ; 3.74(\mathrm{t}, 2 \mathrm{H}$, $\left.-\mathrm{CH}_{2} \mathrm{O}-\right) ; 3.49\left(\mathrm{~m}, 4 \mathrm{H},-\mathrm{CH}_{2} \mathrm{O}-\right)$.
4-[2-(2-Acryloyloxyethoxy)ethoxy]benzoic Acid. A mixture of $5.677 \mathrm{~g}(25.1 \mathrm{mmol})$ of 4-[2-(2-hydroxyethoxy)ethoxy]benzoic acid, $17.1 \mathrm{~mL}(249 \mathrm{mmol})$ of acrylic acid, $1.1 \mathrm{~g}$ of $p$-toluenesulfonic acid, $1.01 \mathrm{~g}$ of 2,6-di-tert-butyl-4-methylphenol, and $40 \mathrm{~mL}$ of chloroform was refluxed at the water separator until no more water was separated. After cooling, the reaction mixture was diluted with chloroform. A part of the product was insoluble and could be isolated by filtration. The solution was extracted with water and dried over sodium sulfate, and the solvent was removed under reduced pressure. The crude product was purified by column chromatography (chloroform).

Yield: $3.97 \mathrm{~g}(57 \%)$ of a colorless solid, mp $129^{\circ} \mathrm{C}$.

FT-IR (ATR): $\tilde{v}=2956,2894(\mathrm{C}-\mathrm{H}), 2658,2561(\mathrm{O}-\mathrm{H})$, $1724,1685(\mathrm{C}=\mathrm{O}), 1605(\mathrm{C}=\mathrm{C}), 1409,1255,1169,1133,1057$, 809, 772.

${ }^{1} \mathrm{H}$ NMR (DMSO- $\left.d_{6}\right): \delta=12.61(\mathrm{bs}, 1 \mathrm{H},-\mathrm{COOH}) ; 7.86(\mathrm{~d}$, $2 \mathrm{H}, \mathrm{Ar}-\mathrm{H}$, ortho to $-\mathrm{COOH}) ; 7.01(\mathrm{~d}, 2 \mathrm{H}$, Ar- $\mathrm{H}$, meta to $-\mathrm{COOH}) ; 6.32\left(\mathrm{dd}, 1 \mathrm{H}, \mathrm{CH}_{2}=\mathrm{CH}-(\right.$ trans $),{ }^{2} \mathrm{~J}=1.9 \mathrm{~Hz},{ }^{3} \mathrm{~J}=$ $17.3 \mathrm{~Hz}) ; 6.17\left(\mathrm{dd}, 1 \mathrm{H}, \mathrm{CH}_{2}=\mathrm{CH}-,{ }^{3} J=17.3 \mathrm{~Hz},{ }^{3} J=9.9 \mathrm{~Hz}\right)$; $5.93\left(\mathrm{dd}, 1 \mathrm{H}, \mathrm{CH}_{2}=\mathrm{CH}-(\mathrm{cis}),{ }^{2} J=1.9 \mathrm{~Hz},{ }^{3} J=9.9 \mathrm{~Hz}\right) ; 4.24(\mathrm{t}$, $\left.2 \mathrm{H},-\mathrm{CH}_{2} \mathrm{O}-\right) ; 4.16\left(\mathrm{t}, 2 \mathrm{H},-\mathrm{CH}_{2} \mathrm{O}-\right) ; 3.77\left(\mathrm{t}, 2 \mathrm{H},-\mathrm{CH}_{2} \mathrm{O}-\right)$; $3.70\left(\mathrm{t}, 2 \mathrm{H},-\mathrm{CH}_{2} \mathrm{O}-\right)$.

4-[2-(2-Acryloyloxyethoxy)ethoxy]benzoic Acid 4-Cyanophenyl Ester (M 1). A solution of $1.497 \mathrm{~g}(5.341 \mathrm{mmol})$ of 4-[2-(2acryloyloxyethoxy)ethoxy]benzoic acid, a pinch of 2,6-di-tert-butyl4-methylphenol, $5 \mathrm{~mL}$ of thionyl chloride and a droplet of DMF was stirred at room temperature for $40 \mathrm{~min}$. Afterwards the excess thionyl chloride was removed under reduced pressure. The residue was suspended in $6 \mathrm{~mL}$ of THF and the suspension was cooled to $0{ }^{\circ} \mathrm{C}$. A solution of $640.8 \mathrm{mg}(5.379 \mathrm{mmol})$ of 4-cyanophenol and $1.1 \mathrm{~mL}$ of triethylamine in $12 \mathrm{~mL}$ of THF was added dropwise at $0{ }^{\circ} \mathrm{C}$. The mixture was stirred for $20 \mathrm{~h}$ at room temperature. Then the solvent was evaporated and the residue was dissolved in 12 $\mathrm{mL}$ of methylene chloride. The organic phase was extracted several times with water and dried over sodium sulfate, and the solvent was removed under reduced pressure. The crude product was purified by column chromatography (hexane/ethyl acetate 2:1).

Yield: $1.05 \mathrm{~g}(52 \%)$ of colorless needles, $\mathrm{mp} 87{ }^{\circ} \mathrm{C}$.

MS $(\mathrm{m} / \mathrm{z}): 381.3\left(\mathrm{M}^{+}\right)$.

$\left(\mathrm{C}_{21} \mathrm{H}_{19} \mathrm{NO}_{6}\right)_{n}(381.4)_{n}$ Calcd C 66.13, H 5.02, N 3.67; Found C 66.17, H 4.94, N 3.70.

FT-IR (ATR): $\tilde{v}=2963,2956,2892(\mathrm{C}-\mathrm{H}), 2230(\mathrm{C} \equiv \mathrm{N}), 1739$, $1726(\mathrm{C}=\mathrm{O}), 1603(\mathrm{C}=\mathrm{C}), 1498,1252,1200,1162,1130,1051$, $844,757$.

${ }^{1} \mathrm{H}$ NMR $\left(\mathrm{CDCl}_{3}\right): \delta=8.11(\mathrm{~d}, 2 \mathrm{H}, \mathrm{Ar}-\mathrm{H}$, ortho to $-\mathrm{COO}-)$; $7.72(\mathrm{~d}, 2 \mathrm{H}, \mathrm{Ar}-\mathrm{H}$, ortho to $-\mathrm{CN}) ; 7.33(\mathrm{~d}, 2 \mathrm{H}, \mathrm{Ar}-\mathrm{H}$, meta to $-\mathrm{CN}) ; 7.00$ (d, $2 \mathrm{H}, \mathrm{Ar}-\mathrm{H}$, meta to $-\mathrm{COO}-) ; 6.42\left(\mathrm{dd}, 1 \mathrm{H}, \mathrm{CH}_{2}=\right.$ $\left.\mathrm{CH}-(\operatorname{trans}),{ }^{2} J=1.5 \mathrm{~Hz},{ }^{3} J=17.3 \mathrm{~Hz}\right) ; 6.14\left(\mathrm{dd}, 1 \mathrm{H}, \mathrm{CH}_{2}=\right.$ $\left.\mathrm{CH}-,{ }^{3} \mathrm{~J}=17.3 \mathrm{~Hz},{ }^{3} \mathrm{~J}=10.3 \mathrm{~Hz}\right) ; 5.83\left(\mathrm{dd}, 1 \mathrm{H}, \mathrm{CH}_{2}=\mathrm{CH}-\right.$ (cis), $\left.{ }^{2} J=1.5 \mathrm{~Hz},{ }^{3} \mathrm{~J}=10.3 \mathrm{~Hz}\right) ; 4.34\left(\mathrm{t}, 2 \mathrm{H},-\mathrm{CH}_{2} \mathrm{O}-\right) ; 4.21(\mathrm{t}$, $\left.2 \mathrm{H},-\mathrm{CH}_{2} \mathrm{O}-\right) ; 3.89$ (t, $\left.2 \mathrm{H},-\mathrm{CH}_{2} \mathrm{O}-\right) ; 3.81\left(\mathrm{t}, 2 \mathrm{H},-\mathrm{CH}_{2} \mathrm{O}-\right.$ ).

${ }^{13} \mathrm{C} \mathrm{NMR}\left(\mathrm{CDCl}_{3}\right): \delta=166.1\left(1 \mathrm{C}, \mathrm{CH}_{2} \mathrm{CHCOO}-\right) ; 163.9(1 \mathrm{C}$, $-\mathrm{COO}-)$; 163.5 (1C, $\mathrm{Ar}-C$, ipso to $\left.-\mathrm{OCH}_{2}-\right)$; $154.4(1 \mathrm{C}, \mathrm{Ar}-$ $C$, para to $\mathrm{CN}) ; 133.7+132.5$ (4C, $\mathrm{Ar}-C$, ortho to $\mathrm{CN}$, meta to $\left.\mathrm{OCH}_{2}\right) ; 131.2\left(1 \mathrm{C}, \mathrm{CH}_{2} \mathrm{CH}-\right) ; 128.2\left(1 \mathrm{C}, \mathrm{CH}_{2} \mathrm{CH}-\right) ; 123.0+$ $121.0\left(3 \mathrm{C}, \mathrm{Ar}-\mathrm{C}\right.$, para to $\mathrm{OCH}_{2}$, meta to $\left.\mathrm{CN}\right) ; 118.3(1 \mathrm{C},-\mathrm{CN})$; 114.6 (2C, $\mathrm{Ar}-C$, ortho to $\left.\mathrm{OCH}_{2}\right) ; 109.6(1 \mathrm{C}, \mathrm{Ar}-C$, ipso to $\mathrm{CN})$; $69.4+67.7+63.5\left(4 \mathrm{C},-\mathrm{CH}_{2}-\right)$.

(S)-2-Chloro-4-methylpentanoic Acid 4'-(11-Acryloyloxyundecyloxy)biphenyl-4-yl Ester (M 12). Monomer M 12 was synthesized in analogy to monomer M 11. ${ }^{13}$

Yield: $72 \%$ of a colorless solid, mp $74^{\circ} \mathrm{C}$.

$[\alpha]_{\mathrm{D}^{20}}=-12.03^{\circ}$ in $\mathrm{CHCl}_{3}\left(c=52.35 \mathrm{~g} \mathrm{~L}^{-1}\right)$.

MS $(\mathrm{m} / \mathrm{z})$ : $542.3\left(\mathrm{M}^{+}\right)$.

Anal. $\left(\mathrm{C}_{32} \mathrm{H}_{43} \mathrm{ClO}_{5}\right)_{n}(543.1)_{n}$ Calcd: C, 70.76; H, 7.98. Found: C, 70.90; H, 7.97.

FT-IR (ATR): $\tilde{v}=2959,2933,2921,2852(\mathrm{C}-\mathrm{H}), 1752,1724$ $(\mathrm{C}=\mathrm{O}), 1606(\mathrm{C}=\mathrm{C}), 1497,1473,1410,1282,1205,1170,1039$, $836,805 \mathrm{~cm}^{-1}$.

${ }^{1} \mathrm{H} \mathrm{NMR}\left(\mathrm{CDCl}_{3}\right): \delta=7.54\left(\mathrm{~d}, 2 \mathrm{H}, \mathrm{Ar}-H\right.$, meta to OOC, ${ }^{3} \mathrm{~J}=$ $8.8 \mathrm{~Hz}) ; 7.46\left(\mathrm{~d}, 2 \mathrm{H}, \mathrm{Ar}-H\right.$, meta to $\left.\mathrm{OCH}_{2},{ }^{3} \mathrm{~J}=8.5 \mathrm{~Hz}\right) ; 7.14$ (d, 
$2 \mathrm{H}, \mathrm{Ar}-H$, ortho to $\left.\mathrm{OOC},{ }^{3} \mathrm{~J}=8.8 \mathrm{~Hz}\right) ; 6.94(\mathrm{~d}, 2 \mathrm{H}, \mathrm{Ar}-H$, ortho to $\left.\mathrm{OCH}_{2},{ }^{3} \mathrm{~J}=8.5 \mathrm{~Hz}\right) ; 6.38$ (dd, $1 \mathrm{H}, \mathrm{CH}_{2}=\mathrm{CH}-$ (trans), ${ }^{2} J=1.5$ $\left.\mathrm{Hz},{ }^{3} \mathrm{~J}=17.5 \mathrm{~Hz}\right) ; 6.10\left(\mathrm{dd}, 1 \mathrm{H}, \mathrm{CH}_{2}=\mathrm{CH}-,{ }^{3} \mathrm{~J}=17.5 \mathrm{~Hz},{ }^{3} \mathrm{~J}=\right.$ $10.3 \mathrm{~Hz}$ ); 5.79 (dd, $1 \mathrm{H}, \mathrm{CH}_{2}=\mathrm{CH}-(\mathrm{cis}),{ }^{2} J=1.5 \mathrm{~Hz},{ }^{3} J=10.3$ $\mathrm{Hz}) ; 4.53$ (t, $1 \mathrm{H},-\mathrm{CHCl}-) ; 4.13\left(\mathrm{t}, 2 \mathrm{H},-\mathrm{COOCH}_{2}-\right) ; 3.97(\mathrm{t}$, $\left.2 \mathrm{H},-\mathrm{OCH}_{2}-\right) ; 1.98\left(\mathrm{~m}, 3 \mathrm{H},-\mathrm{CHCH}_{3}-,-\mathrm{CH}_{2} \mathrm{CH}_{3}-\right) ; 1.81-$ $1.28\left(\mathrm{~m}, 18 \mathrm{H},-\mathrm{CH}_{2}-\right) ; 1.01\left(\mathrm{~m}, 6 \mathrm{H},-\mathrm{CH}_{3}\right)$.

Synthesis of the Colloids. The dispersion polymerization of the monomers was always performed by the same procedure.

In a typical process $50 \mathrm{mg}$ of monomer and $5 \mathrm{mg}$ of the fractionated hydroxypropyl cellulose were degassed for about 20 min with nitrogen in a $10 \mathrm{~mL}$ test tube that was closed with a septum. Then $0.8 \mathrm{~mL}$ of the degassed solvent mixture was added, and the reaction mixture was heated under stirring (700 rpm) to 75 ${ }^{\circ} \mathrm{C}$. About $30 \mathrm{~min}$ later a degassed solution of $5 \mathrm{mg}$ of dibenzoyl peroxide in $0.3 \mathrm{~mL}$ of the solution mixture that had been also heated to $75{ }^{\circ} \mathrm{C}$ before was added to start the polymerization. After a few minutes, the solution turned turbid. The reaction was allowed to proceed for $24 \mathrm{~h}$ and then was ended by opening the test tube and cooling.

One drop of the suspension was used without further purification for the determination of the colloidal particle size with an optical microscope.

For purification the suspension was shortly (approximately 30 s) centrifuged with $2000 \mathrm{rpm}$ and the sediment was isolated. The suspension was further centrifuged, the supernatant was decanted and the colloidal particles were redispersed in ethanol (independent of the used solvent mixture). This procedure was repeated one to two times.

The used solvent mixtures for the different polymerization batches are shown in Table 2.

Synthesis of Colloids by Seed Polymerization. First, $75 \mathrm{mg}$ of monomer M 6 and $7.5 \mathrm{mg}$ of HPC were degassed for about 30 min with nitrogen. Then $1.0 \mathrm{~mL}$ of a degassed mixture of EtOH/ ME 1:1 was added, and the reaction mixture was heated under stirring (700 rpm) to $75^{\circ} \mathrm{C}$. After $45 \mathrm{~min}$, a degassed solution of $7 \mathrm{mg}$ dibenzoyl peroxide in $0.6 \mathrm{~mL}$ of the solution mixture that had been also heated to $75{ }^{\circ} \mathrm{C}$ before was added to start the polymerization. Every $30 \mathrm{~min}, 0.3 \mathrm{~mL}$ of a solution of $250 \mathrm{mg}$ of M 6 in $3 \mathrm{~mL}$ of solution mixture was added (in total nine times). The reaction was ended after $24 \mathrm{~h}$ and purified by centrifugation as described above.

The seed polymerization of monomer M 11 was performed the same way, but pure ethanol was used.

Experiments with Optical Tweezers. We used the same optical tweezers setup as in Sandomirski et al. ${ }^{6}$ and Martin et al. ${ }^{26}$ with a trapping produced by a $\lambda=532 \mathrm{~nm}$ Verdi-V2 frequency-doubled Nd:YAG-Laser (Verdi-V2, Coherent Inc.) and a imaging with a CCD camera (HighSpeedStar1, LaVision $\mathrm{GmbH}$ ). The samples were prepared as follows: The colloid dispersion was highly diluted (volume fraction $<10^{-2}$ ) with a $10 \mathrm{mM}$ aqueous SDS salt solution to prevent particle aggregation. A few drops of this solution were placed in an approximately $170 \mu \mathrm{m}$ thick sample cell, which was hermetically sealed with UV curing glue. The sample was then placed in the optical tweezers and the colloids were trapped at a distance of about 10-20 $\mu \mathrm{m}$ above the bottom cell surface.

The trapping beam was passed through a quarter-wave plate to produce a circularly polarized beam which produced the torque which was transferred to the particle. When a colloid was trapped, a focused unpolarized image was first taken to determine its diameter. Then the imaging polarizers were crossed, and approximately 10000 images were taken at a speed of 30 frames per second. The average time it took for the colloid to rotate $360^{\circ}$ was determined by measuring the intensity fluctuations of the particle in the images which follows $I=\sin ^{2}(2 \theta)$. The results for colloids of the polymers $\mathbf{P} \mathbf{4}, \mathbf{P} \mathbf{6}$, and $\mathbf{P} \mathbf{9}$ are shown in Table 3 .

Acknowledgment. The authors thank the DFG for the support of the work.
Table 3. Diameters, Frequencies, $\log (r)$ and $\log (f)$ for Colloids of $P 4, P$, and P 9

\begin{tabular}{lcccr}
\hline colloid & $d[\mu \mathrm{m}]$ & $f[\mathrm{~Hz}]$ & $\log (r)$ & \multicolumn{1}{c}{$\log (f)$} \\
\hline C 4-1 & 1.8 & 1.52 & -0.046 & 0.180 \\
C 4-2 & 1.8 & 1.63 & -0.046 & 0.211 \\
C 4-3 & 1.9 & 1.43 & -0.022 & 0.154 \\
C 4-4 & 2.0 & 1.30 & 0 & 0.114 \\
C 4-5 & 2.1 & 1.12 & 0.021 & 0.047 \\
C 4-6 & 2.1 & 1.33 & 0.021 & 0.125 \\
C 4-7 & 2.2 & 1.15 & 0.041 & 0.060 \\
C 4-8 & 2.3 & 0.93 & 0.061 & -0.034 \\
C 4-9 & 2.3 & 1.08 & 0.061 & 0.033 \\
C 4-10 & 2.7 & 0.48 & 0.130 & -0.321 \\
C 4-11 & 3.4 & 0.16 & 0.230 & -0.805 \\
C 6-1 & 0.7 & 3.75 & -0.456 & 0.574 \\
C 6-2 & 1.6 & 0.92 & -0.097 & -0.036 \\
C 6-3 & 2.1 & 0.28 & 0.021 & -0.547 \\
C 6-4 & 2.6 & 0.18 & 0.114 & -0.756 \\
C 6-5 & 2.8 & 0.14 & 0.146 & -0.859 \\
C 6-6 & 2.8 & 0.13 & 0.146 & -0.899 \\
C 6-7 & 3.3 & 0.10 & 0.217 & -1.010 \\
C 6-8 & 3.3 & 0.10 & 0.217 & -1.003 \\
C 6-9 & 3.4 & 0.06 & 0.230 & -1.208 \\
C 6-10 & 3.5 & 0.06 & 0.243 & -1.247 \\
C 6-11 & 3.5 & 0.05 & 0.243 & -1.292 \\
C 9-1 & 0.9 & 1.23 & -0.347 & 0.090 \\
C 9-2 & 1.4 & 0.81 & -0.155 & -0.091 \\
C 9-3 & 1.6 & 0.83 & -0.097 & -0.083 \\
C 9-4 & 2.2 & 1.18 & 0.041 & 0.072 \\
C 9-5 & 2.5 & 1.02 & 0.097 & 0.010 \\
C 9-6 & 2.8 & 0.59 & 0.146 & -0.229 \\
C 9-7 & 2.8 & 0.59 & 0.146 & -0.229 \\
C 9-8 & 2.9 & 0.27 & 0.161 & -0.572 \\
C 9-9 & 3.0 & 0.21 & 0.176 & -0.675 \\
C 9-10 & 3.0 & 0.21 & 0.176 & -0.670 \\
C 9-11 & 3.3 & 0.12 & 0.217 & -0.936 \\
9 - - - & & & &
\end{tabular}

Supporting Information Available: Movie 1 showing a dispersion of colloids of $\mathbf{P} \mathbf{6}$ between crossed polarizers. The colloids appear as spots whose brightness fluctuates when they rotate due to Brownian motion, movie 2 showing a $3.3 \mu \mathrm{m}$ colloid of $\mathbf{P} 6(\mathbf{C ~ 6 - 8})$ that was trapped and rotated with an optical tweezers with circularly polarized light, and movie 3 showing a trapped colloid of $\mathbf{P} 9$ that picks up another colloid to orbit around it, which shows the potential of the anisotropic colloids as actuators, and a TEM image showing small smectic colloids (about 50-150 nm) of a "diluted" polysiloxane (see ref 10) with curved and straight smectic layers, where the contrast is due to the silicon in the polymer backbone. This material is available free of charge via the Internet at http://pubs.acs.org.

\section{References and Notes}

(1) Garces-Chavez, V.; McGloin, D.; Summers, M. D.; Fernandez-Nieves, A.; Spalding, G. C.; Cristobal, G.; Dholakia, K. J. Opt. A: Pure Appl. Opt. 2004, 6, S235-238.

(2) Bishop, A. I.; Nieminen, T. A.; Heckenberg, N. R.; RubinszteinDunlop, H. Phys. Rev. Lett. 2004, 92, 198104-1-198104-4.

(3) Cairns, D. R.; Sibulkin, M.; Crawford, G. P. Appl. Phys. Lett. 2001, $78,2643-2645$.

(4) Amimori, I.; Priezjev, N. V.; Pelcovits, R. A.; Crawford, G. P. J. Appl. Phys. 2003, 93, 3248-3252.

(5) Fernández-Nieves, A. Soft Matter 2006, 2, 105-108.

(6) Sandomirski, K.; Martin, S.; Maret, G.; Stark, H.; Gisler, T. J. Phys.: Condens. Matter 2004, 16, S4137-S4144.

(7) Umbanhowar, B. P.; Prasad, V.; Weitz, D. A. Langmuir 2000, 16, 347-351.

(8) Díaz-Leyva, P.; Pérez, E.; Arauz-Lara, J. L. J. Chem. Phys. 2004, 121 (18), 9103-9110.

(9) Fernández-Nieves, A.; Cristobal, G.; Garcés-Chávez, V.; Spalding, G. C.; Dholakia, K.; Weitz, D. A. Adv. Mater. 2005, 17, 680-684

(10) Vennes, M.; Zentel, R.; Rössle, M.; Stepputat, M.; Kolb, U. Adv. Mater. 2005, 17, 2123-2127.

(11) Yang, Z.; Huck, W. T. S.; Clarke, S. M.; Tajbakhsh, A. R.; Terentjev, E. M. Nature mater. 2005, 4, 486-490.

(12) Lok, K. P.; Ober, C. K. Can. J. Chem. 1985, 63, 209-216.

(13) Vennes, M.; Zentel, R. Macromol. Chem. Phys. 2004, 205, 23032311. 
(14) Arshady, R. Colloid Polym. Sci. 1992, 270, 717-732.

(15) Kawaguchi, S.; Ito, K. Adv. Polym. Sci. 2005, 175, 299-328.

(16) Goodby, J. W. Ferroelectric Liquid Crystals; Gordon and Breach Science Publishers: Philadelphia, PA, 1991.

(17) Chovino, C.; Guillon, D.; Gramain, P. Polymer 1998, 39, 6385-6390.

(18) Duran, R.: Gramain, P. Makromol. Chem. 1987, 188, 2001-2009.

(19) Shibaev, V. P.; Kostromin, S. G.; Plate, N. A. Eur. Polym. J. 1982. $18,651-659$.

(20) Jérôme, B.; Commandeur, J.; De Jeu, W. H. Liq. Cryst. 1997, 22, $685-692$.

(21) Portugall, M.; Ringsdorf, H.; Zentel, R. Makromol. Chem. 1982, 183, 2311-2321.
(22) Zentel, R.; Strobl, G. R.; Ringsdorf, H. Macromolecules 1985, 18, 8, 960-965.

(23) Imanishi, Y.; Kondo, K.; Kitamura, T. Jpn. J. Appl. Phys. 1990, 29, L1477-L1479.

(24) Skarp, K.; Andersson, G.; Lagerwall, S. T.; Kapitza, H.; Poths, H.; Zentel, R. Ferroelectrics 1991, 122, 127-137.

(25) Wirick, M. G.; Waldman, M. H. J. Appl. Polym. Sci. 1970, 14, 579597.

(26) Martin, S.; Reichert, M.; Stark, H.; Gisler, T. Phys. Rev. Lett. 2006, submitted.

MA0613279 